\title{
Aspectos atuais da regulação do peso corporal: ação da leptina no desequilíbrio energético
}

\author{
José Donato Júnior, Rogerio Graça Pedrosa, Julio Tirapegui* \\ Departamento de Alimentos e Nutrição Experimental, Faculdade de Ciências Farmacêuticas, \\ Universidade de São Paulo
}

*Correspondência:

J. Tirapegui

Departamento de Alimentos e Nutrição Experimental

Faculdade de Ciências Farmacêuticas Universidade de São Paulo

Av. Prof. Lineu Prestes, 580. Bloco 14 05508-900. São Paulo, SP, Brasil.

E-mail: tirapegu@usp.br
A obesidade já é considerada epidemia global, com taxas de insucesso em seu tratamento a longo prazo de mais de $90 \%$. A descoberta da leptina, um peptídeo sintetizado principalmente pelos adipócitos, abriu novas fronteiras no estudo do tratamento da obesidade. Constatou-se que a leptina, por meio do controle de sua concentração na circulação, poderia ser um sinalizador do estado energético e do tamanho das reservas de gordura, ao atuar em um circuito de retroalimentação, cuja função é de manter o peso corporal estável, independentemente de variações diárias no consumo de energia. Porém, esse circuito apresenta falhas na maioria dos individuos que se tornam obesos (baixa responsividade pela alta concentração de leptina que esses individuos apresentam), o que levou à hipótese da "resistência à leptina". Entretanto, essa revisão sugere que a função fisiológica da leptina é a de um hormônio que "impede" a perda de peso, pois, as repercussões fisiológicas da redução da concentração de leptina são muito mais intensas comparadas ao seu aumento, pelo menos em seres humanos. Dessa forma, o que se convencionou chamar de resistência à leptina expressa apenas ofato, inerente aos seres humanos, de que a elevada concentração de leptina produz somente pequena ação fisiológica.
Unitermos:

- Emagrecimento

- Redução de peso

- Leptina

- Obesidade

- Balanço energético

- Hormônio

\section{INTRODUÇÃO}

O contínuo aumento nas taxas de incidência de pessoas com excesso de peso nas últimas décadas fez com que a obesidade atingisse proporções epidêmicas, a ponto de a Organização Mundial de Saúde (WHO, 2000) considerar a obesidade uma epidemia global (Flegal et al., 2002). Nada menos que $64 \%$ dos norte-americanos adultos podem ser considerados obesos ou com sobrepeso, o que implica gastos da ordem de 99 bilhões de dólares anualmente. Além disso, no mundo, estima-se que existam 300 milhões de obesos e 1 bilhão de pessoas com sobrepeso (Fabricatore, Wadden, 2003). No Brasil, também tem se verificado aumento dos casos de obesidade, sendo que parcela considerável da população pode ser classificada como obesa (Wang et al., 2002). De 1975 até 1997, o número de obesos do sexo masculino na população brasileira quase triplicou $(2,4-6,9 \%)$ e houve aumento de $79 \%$ 
no caso de obesidade entre as mulheres $(7,0-12,5 \%)$. Em ambos os sexos, a média populacional do índice de massa corporal aumentou 2 pontos percentuais durante esse período $\left(22,3-24,3\right.$ e $22,8-24,8 \mathrm{~kg} / \mathrm{m}^{2}$, respectivamente, para homens e mulheres)(Monteiro et al., 2000).

A obesidade está associada a diversas doenças, como por exemplo, diabetes tipo 2, hipertensão arterial, dislipidemia, doenças coronarianas, acidente vascular cerebral e algumas formas de câncer (Kopelman, 2000).

Diante desses dados estarrecedores, muitas pessoas leigas poderiam se perguntar por que uma doença como a obesidade, que "aparentemente" possui tratamento simples, baseado em lógica simplista e enganadora em que bastaria diminuir o quanto se ingere de alimento para tratá-la, não consegue ser combatida? Por que uma pessoa com excesso de peso, que deseja emagrecer e sabe que deve reduzir sua ingestão de alimento para atingir tal meta, simplesmente não o faz? Já para pessoas que possuem um pouco mais de conhecimento nessa área, por que, depois de algum tempo, a maior parte dos indivíduos recupera o peso perdido durante o emagrecimento, aumentando-o ainda mais?

Quem tenta emagrecer ou profissionais da área da saúde que trabalham em programas de redução ponderal responderiam simplesmente que o ato de emagrecer por vontade própria é muito difícil e penoso. Manter o peso estável ao longo do tempo depois de redução do peso corporal (RP) é tarefa igualmente árdua (James, 2002). Assim, pode-se, sem nenhuma dúvida, afirmar que o tratamento da obesidade não só é complexo, mas também é muito difícil de se obter sucesso a longo prazo.

Esse artigo apresentará alguns dos mecanismos conhecidos, pelo qual o organismo age a fim de impedir a RP durante um déficit energético. Mais especificamente, será enfatizada a ação da leptina nos diversos sistemas fisiológicos que regulam a massa corporal. Foi a partir dos estudos deste hormônio que um número crescente de evidências apontaram para o nosso próprio organismo como o "grande inimigo" contra o tratamento da obesidade, pois, ele orquestra eficientemente sistemas fisiológicos capazes de impedir a RP intencional. Deve-se desde já entender que essa ação não decorre de uma falha ou defeito (resistência à leptina), mas de um sistema eficaz desenvolvido para aumentar a sobrevida durante períodos de carência alimentar, como foi demonstrado a partir de estudos com camundongos que não sintetizam leptina e apresentam a característica de serem menos aptos a sobreviver quando sua alimentação é restringida (camundongos homozigotos para a mutação no gene ob, um clássico modelo de camundongos obesos devido à mutação monogênica - chamados de ob/ob (Coleman, 1979)).

\section{Em busca da explicação para a dificuldade de se emagrecer}

De um modo teleológico, o organismo interpreta a RP como uma situação de perigo e ameaça à sobrevivência. Com isso, dispõe de mecanismos eficazes com a finalidade de reduzir ao máximo a RP e, uma vez que haja acesso irrestrito a alimentos, recuperar o peso perdido para estar apto a uma nova e hipotética situação de privação de alimento, como provavelmente ocorria há milhares de anos com nossos antepassados (Padez, 2000). Para os primeiros seres humanos, estar apto a responder eficientemente a períodos de restrição alimentar que deviam ocorrer com freqüência, impedindo a RP, deve ter sido característica importante para garantir a sobrevivência da espécie. Uma vez que nossa bagagem genética ainda remonta às condições dos nossos antepassados de milhares de anos atrás, é de se esperar que essa característica tenha permanecido conosco, porém, inserida atualmente em ambiente muito diferente daquele em que se originou (Flier, 1998).

Essa idéia já foi apresentada por Sharma (1998) e na hipótese de Neel (1962) sobre o genótipo econômico (thrifty genotype), segundo a qual, a carga genética humana e sua conseqüente resposta às mais variadas situações desenvolveram-se em ambiente totalmente diferente do atual (facilidade de acesso a alimentos, principalmente de alta densidade energética, pouca necessidade de atividade física, entre outros etc). Assim, o homem está exposto a fatores que antes não haviam sido "planejados" pelos genes e esses se modificam em um ritmo muito mais lento do que as condições ambientais, promovendo "conflito de interesses" entre aquilo que o organismo foi programado a fazer e aquilo que de fato é o desejo do indivíduo. Essa noção fica evidente numa situação de restrição alimentar voluntária, como por exemplo, em um programa de RP. Enquanto o organismo utiliza diversos mecanismos que amenizam a RP, pois sua prioridade é a sobrevivência e essa hipotética situação é entendida como um risco à vida, estas mesmas adaptações estão prejudicando a intenção do indivíduo, talvez um obeso mórbido, de perder peso (Ravussin, 2002).

Assim, a resposta preferencial do organismo quando submetido ao excesso de alimentos é estocar uma parte desse excedente por meio do depósito de triacilgliceróis no tecido adiposo (TA) para que, em períodos de carência alimentar, o indivíduo possa utilizar esses depósitos como fonte de energia e com isso garantir a sobrevivência (Figura 1)(Obici et al., 2002). Por outro lado, não devia ser interessante que um excesso na ingestão de alimentos causasse prontamente resposta do organismo de igual magnitude a fim de compensar o balanço energético positivo, diminuindo a ingestão de alimentos nas próximas refeições ou au- 


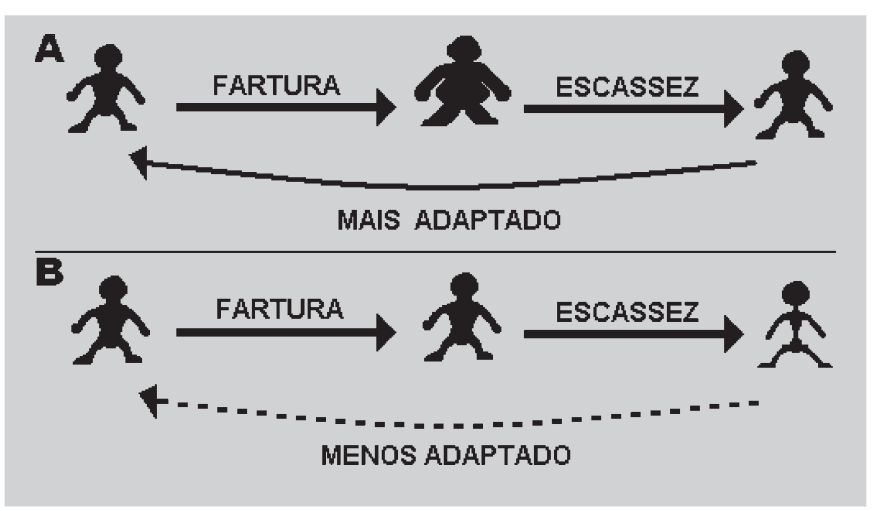

FIGURA 1 - Ilustração de uma situação considerada rotineira na evolução da espécie humana, em que períodos de escassez de alimento deviam ser comuns e cuja conseqüência foi a seleção de indivíduos mais eficientes em termos energéticos. A energia excedente seria armazenada na forma de gordura corporal (Padez, 2000). A-Indivíduos que conseguiam armazenar de modo eficiente o excedente de energia durante períodos de relativa fartura de alimento teriam maior probabilidade de sobreviver a períodos de fome. Porém, essa predisposição a engordar pode ser o componente genético que favorece a obesidade atualmente. B - Indivíduos menos eficientes em converter o excedente de alimento em tecido adiposo, provavelmente não resistiriam a períodos de fome, o que dificultaria que as gerações seguintes herdassem essa característica genética.

mentando o gasto energético (GE). Embora, há muito tempo é fato conhecido que a contra-regulação do organismo ao excesso de alimentos ocorra (Campfield, Smith, 2002), as pessoas que se tornam obesas podem não ser capazes de compensar totalmente esses desequilíbrios entre gasto e consumo, que, no decorrer dos anos, as farão aumentar de peso.

A disparidade entre nossa carga de informação genética e o ambiente em que estamos inseridos no contexto atual é provavelmente a principal causa do grande número de obesos e pessoas com sobrepeso. Diferenças aleatórias no genótipo individual, especialmente na característica de responder a mudanças no saldo do balanço energético (consumo de alimentos versus GE), explicaria, em parte, porque alguns são obesos e outros não, mesmo inseridos em condições ambientais semelhantes. Esse fato é resultado de interação poligênica complexa, embora algumas mutações monogênicas específicas sejam capazes de provocar obesidade ou magreza excessiva (Reitman, 2002).

\section{Regulação do peso corporal}

O ponto-chave para que o tratamento contra a obesidade seja bem-sucedido é que ele deve levar em conta duas etapas: a primeira, que se refere à própria RP, ou seja, redução do TA, principalmente; e a segunda, que diz respeito à manutenção do peso corporal após o emagrecimento. É no cumprimento dessa segunda etapa que estão as maiores dificuldades (Ball et al., 1999). Em poucas palavras, algumas pessoas até conseguem emagrecer significativamente, porém não obtêm o mesmo sucesso quanto à manutenção do novo peso a longo prazo.

Entre os recursos que o organismo pode utilizar para responder a diferentes situações nutricionais estão: a regulação fisiológica do GE e da ingestão energética (IE) (Lowell, Spiegelman, 2000; Schwartz, 2000).

A variação do peso corporal é o resultado de equação simples (Friedman, 2000), porém, existem mecanismos muito complexos que regem as duas variáveis que fazem parte dela (deve ficar claro que certas condições fisiológicas especiais não estão sendo levadas em conta, como o crescimento e a gravidez):

\section{$\Delta$ Peso $=$ Ingestão Energética - Gasto Energético}

Se a IE for maior do que o GE, ocorre acúmulo de gordura no TA. Por outro lado, se o GE for maior que a IE, o organismo terá de oxidar parte dos triacilgliceróis estocados previamente para gerar energia e conseguir suprir as necessidades energéticas necessárias às funções normais do organismo e, conseqüentemente, a RP ocorrerá.

$O$ grande problema decorre da flexibilidade do organismo, que adapta o GE conforme a situação e, com isso, deve ocorrer ajuste proporcional na IE para se conseguir que o peso se mantenha estável, ou, então, o prosseguimento da RP durante um programa de RP (Lowell, Spiegelman, 2000). Alguns autores não consideram o GE muito importante na RP, pois, a variação do GE é muito menos flexível que a da IE, além do que, a diminuição do GE já seria prevista devido à perda de massa magra (MM), que geralmente acompanha a RP (Ballor, Poehlman, 1995).

Porém, a longo prazo, pequenas diminuições de algumas dezenas de kcal do GE, se não compensadas com diminuição proporcional da IE, podem promover ganho significativo de peso, levando ao sobrepeso no decorrer dos anos $^{1}$. Embora exija considerável tempo para que essas pequenas mudanças do GE provoquem resultado consis-

' Um consumo excessivo diário de meros $35 \mathrm{kcal}$ (valor referente à oxidação de 5 gramas de gordura corporal) pode promover ganho de peso na ordem de 18 kg depois de 10 anos, desconsiderando qualquer mecanismo compensatório do organismo. 
tente no peso corporal, elas são tão sutis que estão dentro da margem de erro dos atuais métodos disponíveis para medir o GE. No entanto, grandes reduções de peso são geralmente acompanhadas de significativa redução do GE, na casa das centenas de kcal (Hill et al., 1987).

Blanc et al. (2003), em um estudo com macacos Rhesus (macaca mulatta) submetidos a onze anos de restrição na alimentação, encontraram diminuição significativa da taxa metabólica basal (TMB)(-13\% após ajuste em relação a MM), independente das alterações na composição corporal. Dulloo e Jacquet (1998) também verificaram que indivíduos submetidos a 12 e 24 semanas de restrição diminuíram em $\sim 21 \%$ e $\sim 25 \%$, respectivamente, sua TMB, após ajuste para a MM e TA. Mesmo após 12 semanas de realimentação, esses sujeitos mantinham redução de $\sim 10 \%$ na TMB.

Cohen et al. (2002) estudaram camundongos com dupla mutação, tanto no gene ob quanto no gene que expressa a enzima estearoil-coenzima A dessaturase-1 (stearoyl-coA desaturase-1), que catalisa a biossíntese de ácidos graxos monoinsaturados, e observaram que os animais com a dupla mutação eram mais magros em relação aos seus pares ob/ob. A diferença marcante no peso decorria de um GE elevado, mesmo com IE superior ao grupo controle ob/ob, demonstrando que o GE tem grande relevância na equação do balanço energético.

Igualmente importante é a capacidade do organismo em provocar estímulos fisiológicos para a IE, conforme a situação (Schwartz, 2000). Para tanto, existem sistemas de curto e longo prazo, que controlam a fome e a saciedade. Os de curto prazo, incluem os próprios estímulos sensoriais de paladar e olfato, além de outros sinais provenientes do trato gastrintestinal, como por exemplo, pelos mecano e quimiorreceptores no estômago, que transmitem sinais aferentes via nervo vago até o trato solitário (Jequier, 2002b). Certos hormônios secretados pelo trato gastrintestinal como a colecistoquinina, grelina e enterostatina (Shintani et al., 2001; Horvath et al., 2001), bem como a concentração sérica de insulina e a glicemia (Bellinger, Bernardis, 2002) também são importantes no processo de sinalização de curto prazo, pois, podem, por exemplo, regular o esvaziamento gástrico, a sensação de saciedade, o tempo despendido ou o total ingerido durante uma refeição, além do intervalo entre as refeições (Campfield, Smith, 2002).

Outros sinais de médio e longo prazo informam ao sistema nervoso central (SNC) sobre o estado nutricional e reservas energéticas do organismo. Dentre esses sinalizadores, o hormônio leptina merece destaque.

\section{Leptina}

A leptina é um peptídeo de $16 \mathrm{kDa}$ composto por 169 aminoácidos, sintetizado e secretado principalmente pelas células do TA. Sua identificação e a clonagem de seu gene - gene ob - ocorreram em 1994 (Zhang et al., 1994) e desde então estudos vêm acumulando evidências de que esse hormônio pode ser o eixo do complexo sistema de regulação do balanço energético do organismo (Frühbeck et al., 2001).

Embora a leptina seja um potente anorexígeno, que controla a IE e GE, esse hormônio não pode ser considerado um regulador de curto prazo, pois, não promove alteração do total ingerido no decorrer de uma refeição. Sua resposta ao consumo de alimento tem seu pico somente algumas horas (4-7 horas) após o término da refeição (Hilton, Loucks, 2000).

Quando o gene produtor da leptina foi identificado houve grande especulação e expectativa sobre a possível descoberta da "cura" da obesidade (Flier, 1997), pois, os primeiros experimentos mostravam que a concentração sérica desse hormônio mantinha ótima correlação com o peso corporal e, principalmente, com a quantidade de TA (Friedman, 2000). Além disso, verificou-se que uma linhagem de camundongos homozigotos para mutação no gene $\mathrm{ob}$ - ob/ob - não secretava adequadamente esse hormônio, era obesa e que a reposição hormonal provocava grande RP, fazendo com que seu peso corporal retornasse a valores semelhantes ao de animais normais (Baumann et al., 1996).

Assim, logo após os primeiros estudos com a leptina, pensou-se que ela era a peça perfeita para fechar o circuito de retroalimentação que informava ao organismo a quantidade de energia estocada no TA e com isso desencadear as ações pertinentes referentes a cada situação do balanço energético, explicando o sistema capaz de manter o peso estável na fase adulta. Dessa maneira, se um indivíduo reduz a ingestão de alimentos e/ou aumenta o GE, a síntese de leptina diminui para fazer com que o organismo aumente o estímulo para a ingestão de alimentos e diminua o GE. Por outro lado, se uma pessoa passa a ingerir alimentos excessivamente e/ou reduz seu GE, a concentração sérica de leptina aumenta a fim de promover redução no estímulo de ingestão de alimentos e aumentar o gasto de energia para que o peso permaneça em patamar estável (Figura 2). Dessa forma, uma das primeiras hipóteses testadas foi a de que indivíduos obesos talvez tivessem produção insuficiente de leptina para que o circuito de retroalimentação desse peptídeo na regulação do peso corporal funcionasse perfeitamente (Friedman, 2002). Porém, a expectativa que se formou em torno dessa hipótese logo gerou certa frustração, pois se verificou que, principalmente no caso dos seres humanos, a maior parte dos problemas referentes à obesidade e sua relação com a leptina não 


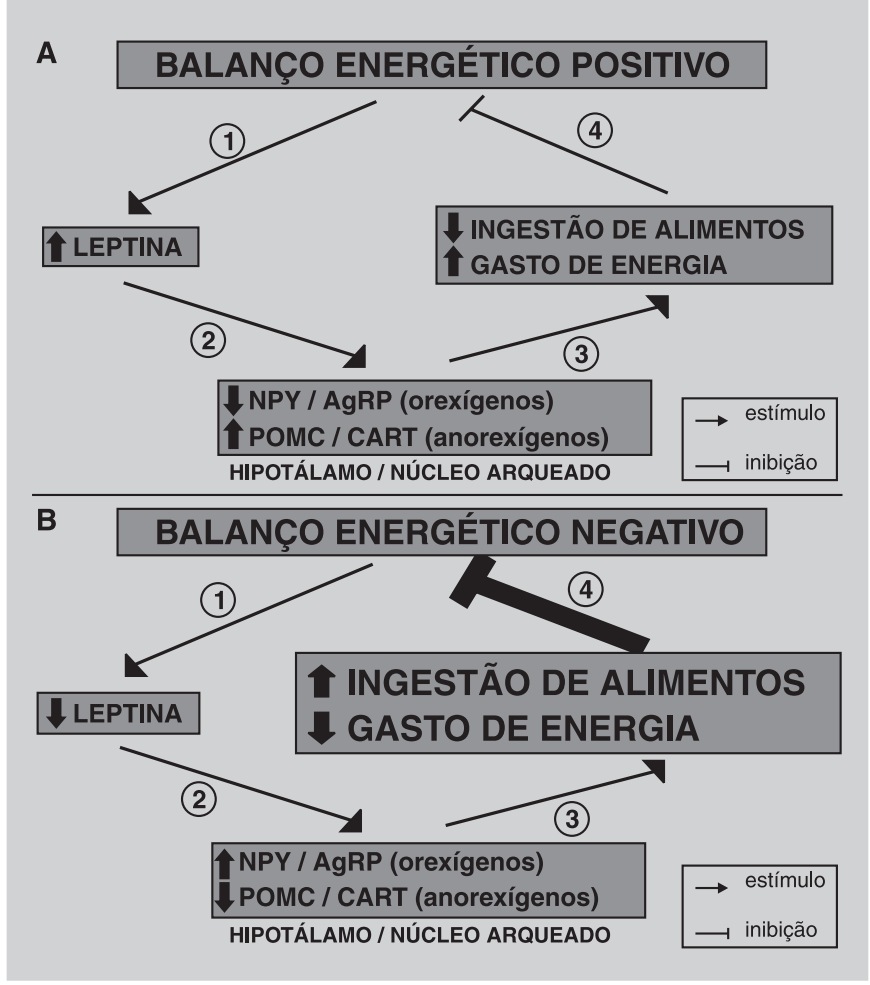

FIGURA 2 - Circuito de retroalimentação entre a concentração sérica de leptina e a regulação do estímulo para a ingestão de alimentos e do gasto energético. A Quando a ingestão de alimentos excede o gasto energético, a concentração de leptina aumenta, levando à diminuição da síntese de NPY e AgRP e ao aumento de POMC e CART no núcleo arqueado (hipotálamo), cuja conseqüência é a diminuição da ingestão de alimentos e o aumento do gasto de energia, a fim de reduzir o balanço energético positivo e, assim, manter o peso estável. B Ilustra situação oposta à anterior, quando a ingestão de energia não consegue suprir a necessidade do gasto de energia, o que implica em aumento do estímulo para a ingestão de alimentos e redução do gasto energético. Notase que as conseqüências fisiológicas do quadro B são muito maiores que a da situação A, ou seja, as repercussões no organismo quando o balanço energético está negativo não são apenas o inverso que no quadro A, mas, também, implicam estímulos muito mais intensos. Abreviaturas: NPY - neuropeptídeo Y; AgRP - proteína relacionada a agouti; POMC - pró-opiomelanocortina; CART - transcrito regulado por cocaína e anfetamina.

decorriam de síntese insuficiente desse hormônio, mas sim, de uma menor sensibilidade e sinalização dos receptores de leptina (OB-R). Esse aspecto ficou evidente em experimentos com uma linhagem de camundongos que não conseguia sintetizar a forma ativa do OB-R (isoforma b), pois possuía um defeito no gene específico - gene $\mathrm{db}$ ( $d i$ abetes gene). Essa linhagem de camundongos $-\mathrm{db} / \mathrm{db}-$ era caracterizada por obesidade, hiperleptinemia e não respondia à administração de leptina exógena (Tartaglia, 1997). Mais especificamente, a linhagem db/db não consegue sintetizar a forma completa do receptor (OB-Rb) caracterizada por 3 subunidades: extracelular, transmembranosa e intracelular. O receptor OB-Rb pode ser abundantemente encontrado principalmente no hipotálamo, nos núcleos arqueado, paraventricular e ventromedial, além da área hipotalâmica lateral (Funahashi et al., 2000).

Além da isoforma OB-Rb, existem pelo menos outras quatro: OB-Ra, OB-Rc, OB-Rd e OB-Re. Essas últimas formas possuem o domínio intracelular incompleto ou ausente e não dispõem de todas as alternativas de sinalização quanto a isoforma OB-Rb. A forma OB-Re possui apenas o domínio extracelular, assim, é solúvel e pode ter função semelhante à de uma proteína ligadora ao transportar a leptina sérica, controlando sua forma livre (Frühbeck et al., 2001).

\section{Ação da leptina}

Uma vez que a leptina é secretada pelas células do TA, ela pode agir centralmente ou na periferia. Nos tecidos periféricos, tem-se estudado a capacidade da leptina em atuar per se na TMB, por meio do estímulo da atividade das proteínas desacopladoras 1, 2 e 3 (uncoupling proteins, UCP-1, UCP-2 e UCP-3), cuja função é a de dissipar parte do gradiente eletroquímico no espaço intermembranoso mitocondrial gerado pelo transporte de elétrons, resultando em perda de energia na forma de calor, e não pelo aproveitamento da energia derivada do alimento na ressíntese do ATP. O TA marrom é um exemplo de tecido, cuja função biológica está intrinsecamente ligada às UCP, principalmente a UCP-1. Ainda não está totalmente esclarecido como a leptina influencia o metabolismo energético e qual é a relação dessas alterações com as UCPs (Gullicksen et al., 2002).

A leptina também atua em grande variedade de tecidos com possíveis efeitos na hematopoiese, no sistema imunológico, no endotélio de vasos sangüíneos, na recuperação de lesões e epitelização, na formação óssea, na homeostase da pressão sangüínea e na atividade lipolítica (Frühbeck, 2002). Essa última função da leptina, um agente que promove estímulo para a lipólise e inibição da lipogênese, vem sendo considerada mecanismo de proteção contra a adipotoxicidade provocada pelo excesso de triacilgliceróis no citossol em células que não são adipócitos e, portanto, não estão preparadas para conter grande quantidade de lipídeos em seu interior. Células com 
excesso de gordura intracelular podem sofrer apoptose e há evidências experimentais que relacionam certas formas de diabetes mellitus com o aumento do conteúdo intracelular de lipídeos (Kelley, GoodPaster, 2001). A ativação da $\mathrm{PKC}-\delta$ (proteína quinase $\mathrm{C}$ delta) parece ser necessária no mecanismo que desencadeia a resistência à insulina provocada pelo excesso de lipídios, em células responsivas à insulina e nas células $\beta$ do pâncreas (Lam et al., 2002; Schmitz-Peiffer, 2002). Além disso, há indícios de que a leptina atua em conjunto com a insulina na regulação do substrato preferencial para geração de energia em tecidos periféricos, como o TA e o tecido muscular. Nesse caso, a leptina provocaria nesses tecidos mudança para a oxidação preferencial de lipídeos, o que hipoteticamente poderia ajudar no controle do peso corporal e na prevenção da obesidade (Ceddia et al., 1998).

No SNC, a leptina age primordialmente no hipotálamo, conhecido como a principal região do SNC que regula os estímulos de fome e saciedade. O núcleo arqueado é considerado o local mais relevante onde a leptina age inibindo a síntese e/ou secreção de neurotransmissores orexígenos - que estimulam a ingestão alimentar - como o neuropeptídio Y (NPY) e a proteína relacionada a agouti (AgRP ou agouti-related protein), um antagonista dos receptores de melanocortina. A leptina também estimula a síntese de pró-opiomelanocortina (POMC), um composto que é precursor do hormônio estimulador de melanócito $\alpha$ ( $\alpha$-MSH ou $\alpha$-melanocyte-stimulating hormone), que possui propriedade anorexígena - diminui o consumo alimentar - ao se ligar aos receptores de melanocortina $3 \mathrm{e}$ 4 (MC3 e MC4)(Friedman, 2000), além do transcrito regulado por cocaína e anfetamina (CART ou cocaine- and amphetamine-regulated transcript).

Simplificadamente, a região hipotalâmica conhecida como núcleo arqueado possui dois tipos de neurônios: um que sintetizam o NPY e AgRP e outro que sintetiza o POMC e CART. Ambos os tipos de neurônios também expressam o OB-Rb. Dessa forma, quando a leptina chega a essas células, ela vai inibir e estimular, respectivamente, esses neurônios, cujo resultado é a diminuição da fome e apetite. Assim, quanto mais leptina circulante, mais se espera que o organismo responda diminuindo a ingestão de alimentos e aumentando o GE, e vice-versa (Figura 2).

Os neurônios que apresentam receptores de leptina no núcleo arqueado possuem axônios que fazem sinapse em outros locais do hipotálamo, como por exemplo, o núcleo hipotalâmico dorsomedial, núcleo hipotalâmico ventromedial, área hipotalâmica lateral, entre outras regiões do cérebro. Por meio das projeções provenientes do núcleo arqueado, há a estimulação de diversos neurotransmissores nessas outras regiões do SNC, como os seguintes orexígenos: orexina (A e B) ou hipocretina e hormônio concentrador de melanina ( $\mathrm{MCH}$ ou melaninconcetrating hormone), ou, então, de anorexígenos como o hormônio liberador de corticotropina (CRH ou corticotropin-releasing hormone), hormônio liberador de tireotropina (TRH ou thyrotropin-releasing hormone) e a interleucina-1 $\beta$ (Friedman, 2002). O controle pela leptina da síntese de CRH e TRH exemplifica como o estado nutricional, mediado pela variação da concentração da leptina, interfere em diversos eixos endócrinos, como, respectivamente, nos eixos hipotálamo-hipófise-adrenal (Vrang et al., 2002) e hipotálamo-hipófise-tireóide (Figura 3)(Flier et al., 2000). Finalmente, os neurotransmissores norepinefrina, serotonina e dopamina também agem na regulação da fome e saciedade, sendo os principais alvos dos fármacos de emagrecimento, presentes atualmente no mercado, que agem no SNC (Halpern, Mancini, 2003).

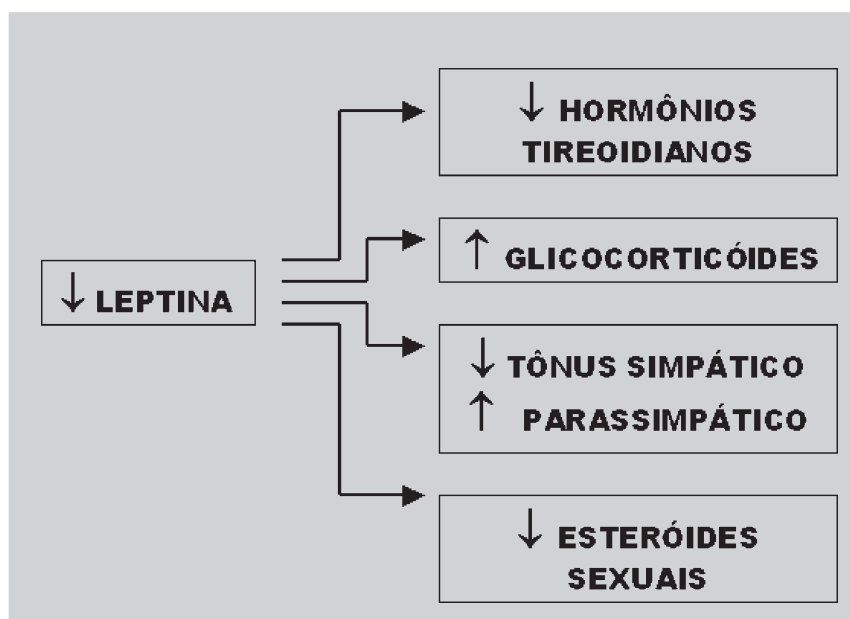

FIGURA 3 - Ação fisiológica da diminuição da leptina sérica na síntese de diversos hormônios. É provável que grande parte das repercussões metabólicas observadas em indivíduos que estão emagrecendo seja causada pela alteração que a leptina provoca na maioria dos eixos endócrinos do organismo.

A leptina possui excelente correlação com a quantidade total de TA. Ou seja, quanto mais gordura corpórea um indivíduo possui, maior será a concentração sérica de leptina. Não são totalmente conhecidos os meios pelos quais há esse controle na secreção de leptina. $\mathrm{O}$ excesso de peso é caracterizado principalmente pela hipertrofia dos adipócitos e em menor proporção pelo aumento no número de células do TA. Assim, há clara evidência que aponta para o papel do tamanho ou volume do adipócito como o estímulo intrínseco que controla a quantidade de leptina que essa célula secreta. Essa hipótese foi validada a par- 
tir de estudos que compararam a secreção de leptina em adipócitos incubados com células de diferentes tamanhos, cuja conclusão foi a de que as amostras com as maiores células sintetizavam mais leptina, comparadas a células menores, mesmo possuindo a mesma massa total (Frühbeck et al., 2001).

Além disso, o tecido adiposo subcutâneo possui maior secreção de leptina que os depósitos abdominais (provavelmente pelo seu maior volume) e a concentração de leptina plasmática em mulheres (pós-puberal) é aproximadamente duas vezes maior que a dos homens, após ajuste pelo peso corporal. Essa diferença é decorrente de maior porcentagem de gordura corpórea, de diferente distribuição do TA pelo corpo (maior quantidade de TA subcutâneo) e da influência dos hormônios sexuais: testosterona inibe a síntese de leptina; progesterona e estrogênio estimulam. Soma-se a tudo isso o fato de a leptina apresentar um ritmo diário de sua concentração bem definido, inverso ao dos glicocorticóides. (Frühbeck et al., 2001).

Embora a leptina tenha recebido grande destaque devido à sua capacidade de sinalizar a quantidade de TA, sua concentração sofre variação agudamente, dependendo principalmente do balanço energético. Seres humanos e outros animais em jejum apresentam acentuada diminuição da concentração sérica de leptina, desproporcional à ínfima diminuição do tecido adiposo sofrida num curto período de jejum. Do mesmo modo, há aumento da leptina circulante em seres humanos após período de consumo excessivo de alimento, porém esse aumento se manifesta de forma mais lenta que em ratos e camundongos (Velkoska et al., 2003). A capacidade da leptina em responder às variações diárias do balanço energético reforça ainda mais o papel desse peptídeo como importante hormônio regulador do peso corporal (Figura 2).

Dessa forma, a leptina assume o mesmo papel em duas diferentes situações, ou seja, sua concentração reflete os depósitos energéticos do organismo, quando o balanço energético está equilibrado, fechando o circuito de retroalimentação do controle ponderal a longo prazo (alta concentração de leptina produziria maior efeito anorexígeno, promovendo a RP; baixa concentração de leptina faria com que os neuropeptídeos orexígenos estivessem aumentados, levando ao aumento do consumo alimentar e ao ganho de peso), mas por outro lado, a leptina deixa de representar os estoques de TA e reflete o balanço energético agudo, quando este está em desequilíbrio, ou seja, quando a IE é diferente do GE.

\section{"Resistência à leptina"}

Apesar do organismo dispor de um sistema de controle de peso aparentemente eficiente como o descrito anteriormente, sem ainda mencionar outros componentes que contribuem para o funcionamento harmônico do balanço energético, algumas pessoas poderiam se perguntar por que a epidemia da obesidade atingiu valores tão elevados. Uma saída encontrada por vários autores para justificar a falha nesse sistema foi atribuir parte da culpa à própria leptina, que, por alguma razão, não estaria desempenhando seu papel conforme o esperado, ou seja, o aumento da concentração sérica de leptina observada nos obesos não provoca os efeitos desejados de redução da IE e aumento do GE, para que o peso se mantivesse estável a longo prazo (Schwartz et al., 2000). Da mesma forma que o diabetes não-insulino dependente é provocado, entre outras coisas, pela diminuição progressiva da sensibilidade à insulina, a obesidade passou a ser encarada como produto da insensibilidade ou resistência à leptina. Essa hipótese ganhou bastante força, pois inúmeros trabalhos demonstravam que os casos de obesidade por falta de leptina eram raríssimos e os seres humanos em grande parte respondiam apenas levemente ao tratamento de leptina exógena, sendo que, na quase totalidade dos obesos estudados, a concentração circulante de leptina estava bastante elevada (Hofbauer, 2002; O'Rahilly, 2002).

Porém, alguns autores propuseram pequena alteração na função fisiológica da leptina e deixaram a atrativa hipótese de resistência à leptina de lado (Jequier, 2002a; Leibel, 2002; Ahima et al., 1996; Spieggelman, Flier, 1996; Flier, Elmquist, 1997). Entretanto, essa pequena alteração implica profunda reformulação de como a regulação corporal deve ser compreendida e propõe novos desafios na busca de soluções no controle da obesidade.

Ao invés de atribuir à leptina a função de um hormônio que regula o balanço energético por meio de um simples circuito de retroalimentação (Ahima et al., 1996), o que condiz com a teoria lipostática ${ }^{2}$, na qual o tecido adiposo produz um sinalizador para o resto do organismo a fim de informá-lo sobre a quantidade das reservas energéticas e assim regular o peso corporal para que fique estável, por meio de mecanismos efetores de controle da IE e GE, a leptina passa a ser entendida como um fator de proteção contra situações de déficit de energia (Jequier, 2002a).

A grande mudança proposta por esses autores diz respeito ao grau de eficiência com que a leptina atua em todo seu intervalo de concentração fisiológico. Em outras

\footnotetext{
${ }^{2}$ A teoria lipostática (ou adipostática) em sua concepção original creditava à concentração sérica de triacilgliceróis e metabólitos derivados de seu catabolismo o papel de veículo para a transmissão de informações referentes às reservas energéticas para o restante do corpo (Kennedy, 1953). A descoberta da leptina acabou por ressuscitar a teoria lipostática devido à sua elevada correlação com a quantidade de gordura estocada no tecido adiposo.
} 
palavras, foi-se questionado se a ação da leptina teria o mesmo poder e eficiência quando sua concentração circulante diminui (baixos estoques de TA, perda de peso ou balanço energético negativo) ou quando ela está aumentada (obesidade, ganho de peso ou balanço energético positivo).

Verificou-se que, ao menos em seres humanos, os efeitos biológicos provocados pela baixa concentração de leptina são muito mais intensos no desencadeamento de reações fisiológicas do que quando sua concentração está aumentada. Assim, a leptina pode ser compreendida como um hormônio de defesa, contra situações de baixa IE, levando a intenso estímulo para o aumento do consumo alimentar e diminuição do GE. Talvez esta seja um agente que prepara o organismo para que, ao haver novamente disponibilidade de alimento, fazer com que se recupere o peso perdido rapidamente e, ainda mais, aumente as reservas energéticas, como salvaguarda contra novos períodos de carência alimentar (Flier, 1998). No entanto, dada as condições prováveis em que o ser humano se desenvolveu no período pré-histórico, em que dificilmente haveria abundância de alimento (Padez, 2000), a ação da leptina em impedir o ganho de peso (como a teoria lipostática propõe) não seria algo positivo, mas justamente o inverso: pessoas menos eficientes em estocar o excedente em períodos de fartura, fatalmente comprometeriam sua sobrevivência quando passassem por tempos de fome (Jequier, 2002a; Flier, 1998).

Portanto, ao considerar a leptina como o eixo do balanço energético, na qual, a variação de sua concentração regula o feedback entre as reservas energéticas e a ingestão alimentar/gasto energético, deve-se também considerar que o aumento de sua concentração tem menores implicações fisiológicas que sua redução (Figura 2). Logo, os indivíduos são muito mais propensos em ganhar peso do que perder nas atuais condições de fácil acesso aos alimentos. Essa constatação vem sendo feita há muito tempo por profissionais da saúde, que tratam pacientes obesos, e pelas próprias pessoas que se submetem a RP. Se por um lado é extremamente penoso reduzir o peso, pois se estará lutando contra o próprio organismo, que possui recursos muito poderosos para impedir que isso ocorra, por outro, no momento em que o tratamento para RP for cessado, a propensão para readquirir o peso perdido será bastante elevada, devido às adaptações que preparam o organismo a recuperar os estoques de energia a patamares semelhantes ao anterior. Não é por acaso que o índice de insucesso de programas de RP é extremamente alto, podendo a chegar a mais de $90 \%$ dependendo do critério adotado (Wing, Hill, 2001; Ayyad, Andersen, 2000). Dessa forma, pode-se considerar a obesidade não só como doença, mas síndrome de difícil tratamento, ao invés de estigmatizar o sujeito obeso como alguém com pouca força de vontade, caráter e determinação, que não consegue nem ao menos manter o próprio peso estável e sucumbe facilmente às tentações da alimentação (Schwartz, Puhl, 2003).

A redução na concentração sérica de leptina e a conseqüente implicação desse estado nos principais eixos hormonais do organismo exemplifica a função fisiológica desse hormônio, atuando principalmente em estados de balanço energético negativo (Figura 3). Flier et al. (2000) verificaram que a diminuição na concentração sérica dos hormônios tireoidianos em períodos de RP são provocadas pela menor concentração de leptina, provavelmente pela ação da leptina no controle da síntese do hormônio liberador de tireotrofina (TRH) no hipotálamo (menor concentração de leptina provoca redução na síntese de TRH). O TRH vai atuar na hipófise estimulando a liberação de tireotrofina (TSH) e esse último hormônio, por sua vez, estimula a produção de tiroxina (T4) e triiodotironina (T3) na glândula tireóide. Esse mecanismo pouparia energia, pois, a manutenção da concentração de T3 e T4 em valores normais ajuda na manutenção da TMB. Parte da redução da TMB durante períodos de emagrecimento pode estar relacionada com a depressão na produção de hormônios tireoidianos (Rosenbaum, 2002). Não há evidências que o aumento da concentração de leptina, como por exemplo, na hiperfagia ou na obesidade, seja capaz de promover alterações significativas na regulação da tireóide (Prentice et al., 2002).

Animais deficientes em leptina (camundongos ob/ob, por exemplo) ou situações que reduzem drasticamente sua concentração, como em períodos de jejum prolongado, aumentam significantemente a síntese de glicocorticóides. Essa alteração na atividade da glândula adrenal também é verificada em seres humanos deficientes ou com baixa concentração de leptina circulante (Vrang et al., 2002). Analogamente à tireóide, não há evidências que mostram que o aumento da concentração de leptina desencadeie alterações de mesma magnitude na adrenal (Prentice et al., 2002).

Uma baixa concentração de leptina pode provocar a redução de certas respostas imunológicas que necessitam de elevado GE, a fim de minimizar a RP ao economizar energia (Lord, 2002), bem como a redução da capacidade reprodutiva (CR), inclusive podendo chegar à interrupção total da CR, como ocorrem nas linhagens de camundongos ob/ob e db/db (Chehab et al., 2002). Resta, ainda saber qual o papel da leptina em mulheres com amenorréia - situação que está relacionada com baixa quantidade de gordura corpórea e, portanto, de leptina - e no processo que desencadeia o início do crescimento para a fase adulta (Hileman et al., 2000). Também, não existe qualquer evidência que o aumento da concentração sérica 
da leptina produza efeitos tão evidentes no sistema imunológico ou na $\mathrm{CR}$ de animais ou seres humanos.

Em todos os exemplos anteriormente citados, a infusão de leptina exógena normaliza o metabolismo dos diferentes eixos endócrinos, mesmo que o animal ou o indivíduo se mantenha em déficit energético (Prentice et al., 2002; Rosenbaum, 2002).

Assim, resumindo, o problema da regulação do peso não reside na falta de autocontrole do indivíduo, mas de uma determinação biológica, que predispõe ao ganho de peso caso o ambiente favoreça essa condição - o que exatamente ocorre na atualidade, em que a abundante disponibilidade de alimentos de alta densidade energética e redução de atividade física imperam - e que, ao se tentar intervir com o intuito de diminuir o peso corporal, o organismo tem plenas condições de responder a essa condição, frustrando boa parte das tentativas de RP. Dessa forma, pode-se dizer que não existe resistência à leptina, mas o poder de ação desse hormônio em concentrações elevadas é menos eficaz, tendo, portanto, ação secundária. No entanto, sua ação principal está relegada às condições de balanço energético negativo, ao evitar qualquer forma de RP, conforme foi exposto nas situações descritas anteriormente.

\section{Controle da responsividade à leptina}

Há diversas hipóteses que tentam explicar a menor capacidade de ação fisiológica da leptina quando esta se encontra em alta concentração circulante (Tabela I). Uma capacidade saturável de transporte da corrente sangüínea pela barreira hemato-encefálica, aos locais que possuem
OB-R no hipotálamo é hipótese interessante. Halaas et al. (1997) verificaram que a resposta a infusões de leptina diretamente no SNC (intracerebroventricular) é mais eficaz que infusões periféricas (subcutânea), talvez pela incapacidade da leptina em transpor a barreira hematoencefálica de modo proporcional ao seu aumento na corrente sangüínea. Kastin e Akerstrom (2001) verificaram que a barreira hemato-encefálica altera a capacidade de transporte de leptina conforme a ingestão de nutrientes, a concentração plasmática de insulina e o jejum prévio. Assim, a mudança na razão entre a concentração periférica e a do SNC poderia ser responsável pela diminuição da responsividade da leptina quando sua concentração aumenta (Mantzoros et al., 1997).

Outro candidato potencial é a retroalimentação negativa entre a concentração de leptina plasmática e o número e/ou atividade dos OB-R. Nesse caso, existe atenção especial voltada à proteína SOCS-3 (supressor do sinal de citocinas 3 ou suppressor of cytokine signalling-3), cuja expressão é aumentada pela ativação dos receptores de citocinas, como é o caso do OB-R, que pertence à superfamília dos receptores de citocina. O SOCS-3 interage com o OB-R, diminuindo sua atividade (Bjørbæk et al., 1998). Assim, quanto maior a ativação do OB-R maior será a síntese de SOCS-3, que, por sua vez, inibe o OB-R, exigindo a necessidade de mais leptina para provocar a mesma ativação que outrora. Esse quadro pode se tornar ciclo vicioso em que, com o passar do tempo, cada vez mais leptina é necessária para provocar a mesma ativação nos seus receptores, aumentando o patamar (setpoint) em que o peso se estabelece (Bjørbæk et al., 1999).

TABELA I - Situações que poderiam reduzir a responsividade fisiológica da leptina em seres humanos, quando em alta concentração sérica

\begin{tabular}{ll}
\hline Local/Situação & Conseqüência \\
\hline $\begin{array}{l}\text { Transporte saturável da barreira } \\
\text { hemato-encefálica }\end{array}$ & $\begin{array}{l}\text { A leptina sintetizada no tecido adiposo não consegue se ligar a seus receptores } \\
\text { (OB-R) no hipotálamo }\end{array}$ \\
SOCS-3 & O SOCS-3 (supressor do sinal de citocinas 3) inibe a sinalização do OB-R \\
Interferência entre a sinalização & $\begin{array}{l}\text { Insulina, citocinas e outras substâncias ao se ligarem a seus receptores implicam } \\
\text { reações que podem interferir com a sinalização do OB-R }\end{array}$ \\
Perda de sensibilidade & $\begin{array}{l}\text { Alta exposição da leptina a seu receptor pode fazer com que a regulação de } \\
\text { neuropeptídeos no hipotálamo seja prejudicada }\end{array}$ \\
Fatores intrínsecos no sangue & $\begin{array}{l}\text { OB-Re e outras substâncias ainda não descobertas poderiam reduzir a } \\
\text { ou no OB-R }\end{array}$ \\
$\begin{array}{l}\text { Mutações (que não interferem na } \\
\text { dosagem por RIE ou ELISA) }\end{array}$ & $\begin{array}{l}\text { Mutações que não impedem o funcionamento dos sistemas que regulam o peso } \\
\text { corporal, mas que reduzem a eficácia desses mecanismos }\end{array}$ \\
\hline
\end{tabular}


É possível que a interferência (cross-talk) entre as reações pós-ativação do OB-R com outras substâncias seja responsável pelo quadro que se convencionou chamar resistência à leptina (Good, 2000). Muitas das reações na cascata de ativação intracelular da leptina com seu receptor também ocorrem na ativação de outros receptores (citocinas, insulina, entre outros)(Sweeney, 2002). Assim, a interferência entre a ativação dos diversos receptores poderia favorecer a diminuição na responsividade da leptina, conforme verificado pela ação do hormônio gastrintestinal orexígeno grelina, que atua nos mesmos neurônios do hipotálamo em que a leptina se liga, efetuando porém ações contrárias àquelas realizadas pela leptina (Traebert et al., 2002). Além disso, a expressão de proteínas que são influenciadas pela ativação do OB-R, como o NPY, cuja síntese é inibida pela leptina, pode ser um local de resistência à leptina. A infusão crônica de leptina no hipotálamo de ratos provoca acentuada redução na quantidade de mRNA do NPY nos primeiros dias. Porém, com o prolongamento da infusão, há tendência da expressão gênica do NPY voltar aos valores normais, a despeito da alta concentração de leptina no SNC (Sahu, 2002).

Finalmente, a presença de fatores intrínsecos e possivelmente desconhecidos no sangue ou nos locais onde há OB-R também pode ser responsável pela diminuição da sensibilidade à leptina. Entre os candidatos, o OB-Re que, possivelmente, se liga à leptina na circulação e é sintetizado em grande quantidade poderia estar interferindo na forma livre/ativa da leptina, alterando a atividade desse hormônio (Ge et al., 2002). Friedman-Einat et al. (2003) estudaram a atividade da leptina sérica em indivíduos obesos e magros e não constataram nenhuma diferença. Esses pesquisadores sugeriam que se houvesse alguma alteração na atividade da leptina sérica, ela seria decorrente de proteínas ligadoras à leptina ou OB-R, antagonistas ou próprias mutações na molécula de leptina ou OB-R, que embora não impedissem a análise quantitativa dessas substâncias por radioimunoensaio, ELISA ou Western Blot (métodos mais empregados), poderia interferir em sua atividade normal, que, provavelmente, estaria diminuída em obesos (Friedman-Einat et al., 2003).

\section{IMPLICAÇÕES PRÁTICAS}

A partir das idéias aqui expostas é possível extrair algumas propostas práticas, que ajudarão a pesquisa nessa área e em programas de RP.

No caso do desenvolvimento de fármacos para o emagrecimento é muito mais provável que os resultados sejam mais promissores se processos posteriores (downstream) à ligação da leptina a seu receptor sejam focados e não nela especificamente, pois, como já foi exposto, a capacidade da leptina em provocar RP é limitada, sendo obtido geralmente com doses suprafisiológicas e, ainda assim, com eficácia a longo prazo duvidosa (Hukshorn et al., 2003). Desse modo, se um fármaco agisse em reações após a ligação da leptina a seu receptor, a "barreira" que esse hormônio exerceria seria reduzida. Porém, não seria impedida uma contra-regulação do organismo, por meio de acentuada redução da concentração sérica de leptina. Talvez, fármacos que atuem em diversos locais, ou então, um coquetel de medicamentos que também suavize a provável contra-regulação do organismo tenha mais sucesso no futuro. Além disso, o uso de leptina exógena pode ser uma alternativa para indivíduos que reduziram seu peso e desejam mantê-lo estável, pois, a concentração sérica de leptina se mantém reduzida após um programa de RP e se acredita que as conseqüências desencadeadas pela baixa concentração de leptina sérica sejam responsáveis pela propensão à recuperação do peso corporal que foi perdido (Rosenbaum et al., 2002). Assim, a infusão de leptina exógena pode ser eficiente na manutenção do peso estável após a RP e não como terapia medicamentosa para se perder peso.

Além disso, o conhecimento prático que muitos que tratam a obesidade possuem e é corroborado pelas informações desse trabalho diz respeito ao aumento das probabilidades de sucesso de se emagrecer e não recuperar o peso perdido quando existe uma estrutura (pessoas ou profissionais que dêem apoio ou informação, entre outros) com que o paciente possa contar (Fabricatore, Wadden, 2003). Isso se deve principalmente à necessidade de suporte, pois, em última análise, emagrecer voluntariamente vai contra o próprio organismo, que possui mecanismos poderosos para impedir que isso ocorra, pois, simplesmente não há meios de se diferenciar a necessidade de se perder peso - como na obesidade - com uma situação de falta real de alimento. Assim, ter um programa estruturado e contar com a ajuda de profissionais da área da saúde é fundamental para aumentar a probabilidade de sucesso para perder peso.

\section{CONSIDERAÇÕES FINAIS}

A obesidade é antes de tudo uma doença muito complexa, que tem como causa um componente genético poligênico e outro ambiental. A obesidade não é um distúrbio somente genético, pois, há poucas décadas a quantidade de pessoas com sobrepeso e obesidade era apenas fração do que é hoje e, portanto, nosso conteúdo genético não pode ter se modificado numa velocidade tão grande. Mas, a questão é que o ambiente é muito diferente daquele 
no passado, principalmente no que se refere à alimentação - fácil acesso e aumento da contribuição de alimentos densamente energéticos, com diminuição do consumo de fibras alimentares - e redução da atividade física. Somente a modificação do ambiente também não consegue explicar a epidemia de obesidade, pois mesmo que o número de casos de obesidade e sobrepeso seja imenso, boa parte da população ainda possui peso normal. A grande questão é: por que alguns engordam e outros não, uma vez que praticamente todos estão expostos às mesmas condições que predispõem ao ganho de peso?

A resposta mais racional e simples é que as pessoas, e portanto seu genótipo, respondem de modo diferente a determinadas situações: uns podem ganhar peso ao se depararem com as condições ambientais em que vivemos, desde que sua carga genética predisponha a isso, mas outras não. A estigmatização do obeso, principalmente no que se refere ao tratamento do excesso de peso, geralmente não leva em conta que a partir dessas diferentes características genéticas, para alguns é mais fácil perder peso e para outros missão de extrema dificuldade. Além disso, fatores ambientais e psico-sociais, tais como, escolaridade, renda, nível de informação sobre alimentação, menor tempo para as refeições, estresse, menor atividade física, também são determinantes na predisposição individual em ganhar peso e na dificuldade de poder tratar a condição de excesso de peso. Assim, todos esses fatores devem ser considerados na hora de estabelecer metas e o tratamento mais adequado para cada um, impedindo que o insucesso de tentativas frustradas de perder peso do passado seja impecilho para que se tente novamente. Porém, com um apoio adequado, sem se deixar levar por modismos ou falsas esperanças em tratamentos que prometem muito, mas não têm comprovação científica e que inclusive põem em risco a saúde dos pacientes.

Esse artigo procurou contribuir com informações referentes à leptina e seu papel relevante na regulação do peso, não por controlar os estoques de TA, como proposto pela adaptação à teoria lipostática, mas por sinalizar ao SNC condições de balanço energético negativo. O resultado final é a promoção de ajustes, que diminuem o quanto se perde de peso, seja por meio de economia de energia via diminuição do GE, seja pelo aumento do estímulo para a ingestão de alimentos. Em poucas palavras, sugere-se que a leptina deixe de ser compreendida somente como um sinalizador do TA para informar ao SNC sobre a quantidade de energia estocada e passe a ser entendida também como um hormônio de função protetora para preparar o organismo, quando esse está exposto a condições de ingestão insuficiente de energia.
Finalmente, a leptina é apenas parte de um complexo sistema que regula a ingestão alimentar e metabolismo energético. Assim, muitos outros componentes também interagem com a leptina na sinalização do estado nutricional. Uma vez que se busca a compreensão desse sistema, todas as partes que o formam e suas respectivas interações devem ser levadas em consideração.

\section{AGRADECIMENTOS}

Os autores agradecem ao CNPq, à CAPES e à FAPESP pelo apoio financeiro.

\section{ABSTRACT}

\section{Recent aspects of body weight regulation: leptin's action on the energetic misbalance}

Nowadays obesity can be considered a global epidemic illness, though it shows a long-term treatment failure index higher than 90\%. Research work on leptin, which is a peptide mainly produced by fat cells, lead to a breakthrough for medical obesity treatment. It has been found out that leptin - through control of its concentration, could be a marker of the energetic status and depot of fat amounts in cells as well. This occurs by acting in a feedback circuit which function is to maintain body weight stable - this independently of food intake variations. Hence, if this circuit presents failures, as i.e. low response to high leptin concentration, patients may become obese. This phenomenon is very common and lead to the "leptin resistance thesis". The aim of this review is to explain leptin's physiological function as an hormone that "prevents" weight loss because physiological repercussion of leptin concentration reduction seems to be more intense than when it increases - at least in human beings. Therefore what has been called - by definition - leptin resistance - seems to be just the result of a concentration which causes a limited physiological action.

UNITERMS: Weight loss. Leptin. Obesity. Energy balance. Hormone.

\section{REFERÊNCIAS BIBLIOGRÁFICAS}

AHIMA, R. S., PRABAKARAN, D., MANTZOROS, C., QU, D., LOWELL, B., MARATOS-FLIER, E., FLIER, J. S. Role of leptin in the neuroendocrine response to fasting. Nature, v.382, p.250-252, 1996. 
AYYAD, C., ANDERSEN, T. Long-term efficacy of dietary treatment of obesity: a systematic review of studies published between 1931 and 1999. Obes. Rev., v.1, p.113$119,2000$.

BALL, G. D. C., GINGRAS, J. R., FIMRITE, A., VILLETARD K., KAYMAN S., MCCARGAR L. J. Weight relapsers, maintainers, and controls: metabolic and behavioral differences. Can. J. Appl. Physiol., v.24, p.548-558, 1999.

BALLOR, D. L., POEHLMAN, E. T. A meta-analysis of the effects of exercise and/or dietary restriction on resting metabolic rate. Eur. J. Appl. Physiol., v.71, p.535-542, 1995.

BAUMANN, H., MORELLA, K. K., WHITE, D. W., DEMBSKI, M., BAILON, P. S., KIM, H., LAI, C. F., TARTAGLIA, L. A. The full-length leptin receptor has signaling capabilities of interleukin 6-type cytokine receptors. Proc. Natl. Acad. Sci. USA., v.93, p.83748378, 1996.

BELLINGER, L. L., BERNARDIS, L. L. The dorsomedial hypothalamic nucleus and its role in ingestive behavior and body weight regulation: Lessons learned from lesioning studies. Physiol. Behav., v.76, p.431-442, 2002.

BJØRBÆK, C., EL-HASCHIMI, K., FRANTZ, J. D., FLIER, J. S. The role of SOCS-3 in leptin signaling and leptin resistance. J. Biol. Chem., v.274, p.30059-30065, 1999.

BJØRBÆK，C., ELMQUIST, J., FRANTZ, J., SHOELSON, S., FLIER, J. Identification of SOCS-3 as a potential mediator of central leptin resistance. Mol. Cell., v.1,p.619-625, 1998.

BLANC, S., SCHOELLER, D., KEMNITZ, J., WEINDRUCH, R., COLMAN, R., NEWTON, W., WINK, K., BAUM, S., RAMSEY, J. Energy expenditure of rhesus monkeys subjected to 11 years of dietary restriction. J. Clin. Endocrinol. Metab., v.88, p.16-23, 2003.

CAMPFIELD, L. A., SMITH, F. J. Blood glucose dynamics and control of meal initiation: a pattern detection and recognition theory. Physiol. Rev., v.83, p.25-58, 2002.
CEDDIA, R. B., WILLIAN JUNIOR, W. N., LIMA, F. B., CARPINELLI, A. R., CURI, R. Pivotal role of leptin in insulin effects. Braz. J. Med. Biol. Res., v.31, p.715-722, 1998.

CHEHAB, F. F., QIU, J., MOUNZIH, K., EWARTTOLAND, A., OGUS, S. Leptin and reproduction. Nutr. Rev., v.60, p.S39-S46, 2002.

COHEN, P., MIYAZAKI, M., SOCCI, N. D., HAGGEGREENBERG, A., LIEDTKE, W., SOUKAS, A. A., SHARMA, R., HUDGINS, L. C., NTAMBI, J. M., FRIEDMAN, J. M. Role for stearoyl-coA desaturase-1 in leptin-mediated weight loss. Science, v.297, p.240-243, 2002.

COLEMAN, D. Obesity genes: beneficial effects in heterozygous mice. Science, v.203, p.663-665, 1979.

DULLOO, A. G., JACQUET, J. Adaptive reduction in basal metabolic rate in response to food deprivation in humans: a role for feedback signals from fat stores. Am. J. Clin. Nutr., v.68, p.599-606, 1998

FABRICATORE, A. N., WADDEN, T. A. Treatment of obesity: an overview. Clin. Diabetes. v.21, p.67-72, 2003.

FLEGAL, K. M., CARROL, M. D., OGDEN, C. L., JOHNSON, C. L. Prevalence and trends in obesity among U.S. adults, 1999-2000. JAMA. J. Am. Med. Assoc., v.288, p.1723-1727, 2002.

FLIER, J. S. Leptin expression and action: new experimental paradigms. Proc. Natl. Acad. Sci. USA., v.94, p.4242$4245,1997$.

FLIER, J. S. What's in a name? In search of leptin's physiologic role. J. Clin. Endocrinol. Metab., v.83, p.1407-1413, 1998.

FLIER, J. S., ELMQUIST, J. K. Energetic pursuit of leptin function. Nat. Biotechnol., v.15, p.20-21, 1997.

FLIER, J. S., HARRIS, M., HOLLENBERG, A. N. Leptin, nutrition, and the thyroid: the why, the wherefore, and the wiring. J. Clin. Invest., v.105, p.859-861, 2000.

FRIEDMAN, J. M. Obesity in the new millennium. Nature, v. 404, p.632-634, 2000. 
FRIEDMAN, J. M. The function of leptin in nutrition, weight, and physiology. Nutr. Rev., v.60, p.S1-S14, 2002.

FRIEDMAN-EINAT, M., CAMOIN, L., FALTIN, Z., ROSENBLUM, C. I., KALIOUTA, V., ESHDAT, Y., STROSBERG, A. D. Serum leptin activity in obese and lean patients. Regul. Pept., v.111, p.77-82, 2003.

FRÜHBECK, G., GÓMEZ-AMBROSI, J., MURUZÁBAL, F. J., BURRELL, M. A. The adipocyte: a model for integration of endocrine and metabolic signaling in energy metabolism regulation. Am. J. Phisiol. Endocrinol. Metab., v.280, p-E827-E847, 2001.

FRÜHBECK, G. R. Peripheral actions of leptin and its involvement in disease. Nutr. Rev., v.60. p.S47-S55. 2002.

FUNAHASHI, H., RYUSHI, T., MIZUSHIMA, H., KATOH, S., SHIODA, S. Ultrastructural localization of the receptor for leptin in the rat hypothalamus. Horm. Behav., v.37, p.327-334, 2000.

GE, H., HUANG, L., POURBAhrAmi, T., LI, C. Generation of soluble leptin receptor by ectodomain shedding of membrane-spanning receptors in vitro and in vivo. J. Biol. Chem., v.277, p.45898-45903, 2002.

GOOD, D. J. How tight are your genes? Transcriptional and posttranscriptional regulation of the leptin receptor, NPY, and POMC genes. Horm. Behav., v.37, p.284-298, 2000.

GULLICKSEN, P. S., FLATT, W. P., DEAN, R. G., HARTZELL, D. L., BAILE, C. A. Energy metabolism and expression of uncoupling proteins 1, 2, and 3 after 21 days of recovery from intracerebroventricular mouse leptin in rats. Physiol. Behav., v.75, p.473-482, 2002.

HALAAS, J. L., BOOZER, C., BLAIR-WEST, J., FIDAHUSEIN, N., DENTON, D. A., FRIEDMAN, J.M. Physiological response to long-term peripheral and central leptin infusion in lean and obese mice. Proc. Natl. Acad. Sci. USA, v.94, p.8878-8883, 1997.

HALPERN, A., MANCINI, M. C. Treatment of obesity: an update on anti-obesity medications. Obes. Rev., v.4, p.2542, 2003.

HILEMAN, S. M., PIERROZ, D. D., FLIER, J. S. Leptin, nutrition, and reproduction: timing is everything. J. Clin. Endocrinol. Metab., v.85, p.804-807, 2000.
HILL, J. O., SPARLING, P. B., SHIELDS, T. W., HELLER, P. A. Effects of exercise and food restriction on body composition and metabolic rate in obese women. Am. J. Clin. Nutr., v.46, p.622-30, 1987.

HILTON, L. K., LOUCKS, A. B. Low energy availability, not exercise stress, supresses the diurnal rhythm of leptin in healthy young women. Am. J. Physiol. Endocrinol. Metab., v.278, p.E43-E49, 2000.

HOFBAUER, K. G. Molecular pathways to obesity. Int. J. Obes., v.26, supl. 2, p.S18-S27, 2002.

HORVATH, T. L., DIANO, S., SOTONYI, P., HEIMAN, M., TSCHÖP, M. Minireview: ghrelin and the regulation of energy balance - a hypothalamic perspective. Endocrinol., v.142, p.4163-4169, 2001.

HUKSHORN, C. J., WESTERTERP-PLANTENGA, M., SARIS, W. H. M. Pegylated human recombinant leptin (PEG-OB) causes additional weight loss in severely energy-restricted, overweight men. Am. J. Clin. Nutr., v.77, p.771-776, 2003.

JAMES, P. Discussion (Nineteenth Marabou Symposium; Leptin: a key regulator in nutrition; Sundbyberg, Sweden). Nutr. Rev., v.60, p.S68-S84, 2002.

JEQUIER, E. Leptin signaling, adiposity, and energy balance. Ann. N. Y. Acad. Sci., v.967, p.379-388, 2002a.

JEQUIER, E. Pathways to obesity. Int. J. Obes., v.26, p.S12S17, 2002b.

KANT, A. K. Weight-loss attempts and reporting of foods and nutrients, and biomarkers in a national cohort. Int. J. Obes., v.26, p.1194-1204, 2002

KASTIN, A. J., AKERSTROM, V. Glucose and insulin increase the transport of leptin through blood-brain barrier in normal mice but not in streptozotocin-diabetic mice. Neuroendocrinol., v.73, p.237-242, 2001.

KELLEY, D. E., GOODPASTER, B. H. Skeletal muscle triglyceride: an aspect of regional adiposity and insulin resistance. Diabetes Care, v.24, p.933-941, 2001.

KENNEDY, G. C. The role of depot fat in the hypothalamic control of food intake in the rat. Proc. R. Soc. Lond. B. Sci..v.140, p.578-592, 1953. 
KOPELMAN, P. G. Obesity as a medical problem. Nature, v.404,p.635-643, 2000.

LAM, T. K., YOSHII, H., HABER, C. A., BOGDANOVIC, E., LAM, L., FANTUS, I.G., GIACCA, A. Free fatty acid-induced hepatic insulin resistance: a potencial role for protein kinase C-d. Am. J. Physiol. Endocrinol. Metab., v.283,p.E682-691, 2002.

LEIBEL, R.L. The role of leptin in the control of body weight. Nutr. Rev., v.60, p.S15-S19, 2002.

LORD, G. Role of leptin in immunology. Nutr. Rev.,v.60, p.S35S38, 2002.

LOWELL, B.B., SPIEGELMAN, B.M. Towards a molecular understanding of adaptive thermogenesis. Nature, v.404, p.652-660, 2000.

MANTZOROS, C., FLIER, J.S., LESEM, M.D., BREWERTON, T.D., JIMERSON, D.C. Cerebrospinal fluid leptin in anorexia nervosa: correlation with nutritional status and potential role in resistance to weight gain. $J$. Clin. Endocrinol. Metab., v.82, p.1845-1851, 1997.

MONTEIRO, C.A., BENICIO, M.H.D'A., CONDE, W.L., POPKIN, B.M. Shifting obesity trends in Brazil. Eur. J. Clin. Nutr., v.54, p.342-346, 2000.

NEEL, J. Diabetes mellitus: a "thrifty" genotype rendered detrimental by "progress". Am. J. Hum. Genet., v.14, p.353-362, 1962.

O'RAHILLY, S. Leptin: defining its role in humans by the clinical study of genetic disorders. Obes. Rev., v.60, p.S30S34, 2002.

OBICI, S., WANG, J., CHOWDURY, R., FENG, Z., SIDDHANTA, U., MORGAN, K., ROSSETI, L. Identification of a biochemical link between energy intake and energy expenditure. J. Clin. Invest., v.109, p.1599$1605,2002$.

PADEZ, C. Uma perspectiva antropológica da obesidade. Antrop. Port., v.16/17, p.145-159, 1999/2000.

PRENTICE, A.M., MOORE, S.E., COLLINSON, A.C., O'CONNELL, M.A. Leptin and undernutrition. Nutr. Rev., v.60, p.S56-S67, 2002.
RAVUSSIN, E. Cellular sensors of feast and famine. J. Clin. Invest., v.109, p.1537-1540, 2002.

REITMAN, M.L. Metabolic lessons from genetically lean mice. Annu. Rev. Nutr., v.22, p.459-482, 2002.

ROSENBAUM, M., MURPHY, E.M., HEYMSFIELD, S.B., MATTHEWS, D.E., LEIBEL, R.L. Low dose leptin administration reverses effects of sustained weightreduction on energy expenditure and circulating concentrations of thyroid hormones. J. Clin. Endocrinol. Metab., v.87, p.2391-2394, 2002.

SAHU, A. Resistance to the satiety action of leptin following chronic central leptin infusion is associated with the development of leptin resistance in neuropeptide $\mathrm{Y}$ neurons. J. Neuroendocrinol., v.14, p.796-804, 2002.

SCHMITZ-PEIFFER, C. Protein kinase C and lipid-induced insulin resistance in skeletal muscle. Ann. N.Y. Acad. Sci., v.967, p.146-157, 2002

SCHWARTZ, M.B., PUHL, R. Childhood obesity: a societal problem to solve. Obes. Rev., v.4, p.57-71, 2003.

SCHWARTZ, M.W., WOODS, S.C., PORTE JR., D., SEELEY, R.J., BASKIN, D.G. Central nervous system control of food intake. Nature, v.404, p.661-671, 2000.

SHARMA, A.M. The thrifty-genotype hypothesis and its implications for the study of complex genetic disorders in man. J. Mol. Med., v.76, p.568-571, 1998.

SHINTANI, M., OGAWA, Y., EBIHARA, K., AIZAWAABE, M., MIYANAGA, F., TAKAYA, K., HAYASHI, M., INOUE, G., HOSODA, K., KOJIMA, M., KANGAWA, K., NAKAO, K. Ghrelin, an endogenous growth hormone secretagogue, is a novel orexigenic peptide that antagonizes leptin action through the activation of hypothalamic neuropeptide $\mathrm{Y} / \mathrm{Y} 1$ receptor pathway. Diabetes, v.50, p.227-232, 2001.

SPIEGELMAN, B., FLIER, J. Adipogenesis and obesity: rounding out the big picture. Cell, v.87, p.377-389, 1996.

SWEENEY, G. Leptin signalling. Cell. Signal., v.14, p.655$663,2002$.

TARTAGLIA, L.A. The leptin receptor. J. Biol. Chem., v.272, p.6093-6097, 1997. 
TRAEBERT, M., RIEDIGER, T., WHITEBREAD, S; SCHARRER, E., SCHIMID, H.A. Ghrelin acts on leptinresponsive neurones in the rat arcuate nucleus. $J$. Neuroendocrinol., v.14, p.580-586, 2002.

VELKOSKA, E., MORRIS, M.J., BURNS, P., WEISINGER, R.S. Leptin reduces food intake but does not alter weight regain following food deprivation in the rat. Int. J. Obes., v.27, p.48-54, 2003.

VRANG, N., KRISTENSEN, P., TANG-CHRISTENSEN, M., LARSEN, P.J. Effects of leptin on arcuate proopiomelanocortin and cocaine-amphetamine-regulated transcript expression are independent of circulating levels of corticosterone. J. Neuroendocrinol., v.14, p.880-886, 2002.
WANG, Y., MONTEIRO, C., POPKIN, B.M. Trends of obesity and underweight in older children and adolescents in the United States, Brazil, China, and Russia. Am. J. Clin. Nutr., v.75, p.971-977. 2002.

WING, R.R., HILL, J.O. Successful weight loss maintenance. Annu. Rev. Nutr., v.21, p.323-341, 2001.

WORLD HEALTH ORGANIZATION. Obesity: preventing and managing the global epidemic. Tech. Rep., Geneve, v. 894, p. 1-23, 2000.

ZHANG, Y., PROENCA, R., MAFFEI, M., BARONE, M., LEOPOLD, L., FRIEDMAN, J.M. Positional cloning of the mouse obese gene and its human homologue. Nature, v.372, p.425-432, 1994.

Recebido para publicação em 03 de março de 2004. Aceito para publicação em 08 de julho de 2004. 